\title{
The role of combined computed tomographic angiography and digital subtraction angiography in the management of cervico-facial vascular lesions
}

\author{
Ahmed Mostafa Mohamed Kassem ${ }^{1 *}$ (i), Alaa Mohamed Fathy², Abdel Aziz Mohamed Alnekidy², \\ Mohamed Ahmed Morsy ${ }^{3}$ and Mohamed Mahmoud El Shafei ${ }^{2}$
}

\begin{abstract}
Background: Cervicofacial vascular lesions are one of the most challenging diseases managed by intervention radiologists and specialized surgeons. These lesions were diagnosed to be vascular in origin by other imaging techniques such as Duplex and/or magnetic resonance imaging (MRI). All patients underwent computed tomographic angiography (CTA) to confirm the diagnosis as well as to decide the most effective choice of management based on multidisciplinary team (MDT). Then, Digital subtraction angiography (DSA) was done as it is offering an accurate vascular map for the vascular lesions which is inevitable for successful super-selective endovascular embolization which can be done at same sitting. Small cases of arteriovenous malformations (AVMs) were sufficiently managed by only embolization, whereas cases of adequately embolized large AVMs as well as juvenile nasopharyngeal angiofibroma (JNA) cases were followed by surgery with the advantage of less blood loss and decreasing operation time as well as complications. This prospective study was done to highlight the role of combined CTA and DSA in cervicofacial vascular lesion management.

Results: Twenty patients were included in our study: 16 patients were males, and 4 were females; 17 of them were under 40 years, and three were above 40 years. Preoperative embolization was done in 12 patients, which were all the cases of JNAs and large AVMs. Four patients were managed by only embolization as a definitive treatment. Complete technical success rate was about 94\%, while only $6 \%$ (single case) of the partial technical success rate which was due to a very small accessory feeder that could not be catheterized even with repeated trials.
\end{abstract}

Conclusions: Combined CTA and DSA is the cornerstone for managing vascular lesions in the cervicofacial region, which necessitates a MDT to decide the most beneficial and least complicated way for management.

Keywords: Vascular lesions, CTA, DSA, Embolization

\footnotetext{
* Correspondence: Ahmed.mm_kassem@hotmail.com

'Department of Diagnostic and Interventional Radiology, Faculty of

Medicine, Port-Said University, Port-Said, Egypt

Full list of author information is available at the end of the article
}

\section{Springer Open}

(0) The Author(s). 2021 Open Access This article is licensed under a Creative Commons Attribution 4.0 International License, which permits use, sharing, adaptation, distribution and reproduction in any medium or format, as long as you give appropriate credit to the original author(s) and the source, provide a link to the Creative Commons licence, and indicate if changes were made. The images or other third party material in this article are included in the article's Creative Commons licence, unless indicated otherwise in a credit line to the material. If material is not included in the article's Creative Commons licence and your intended use is not permitted by statutory regulation or exceeds the permitted use, you will need to obtain permission directly from the copyright holder. To view a copy of this licence, visit http://creativecommons.org/licenses/by/4.0/. 


\section{Background}

Vascular lesions, especially in the cervicofacial region, are rare, yet they are one of the most challenging diseases treated by intervention radiologists and specialized surgeons $[1,2]$.

The International Society for the Study of Vascular Anomalies (ISSVA) classifies vascular lesions into main two groups, vascular neoplasm (true proliferative neoplasms) and vascular malformation (defects in morphogenesis) [3].

Accurate diagnosis is depending on a combination of clinical features with different imaging techniques, including Duplex, computed tomographic angiography (CTA), MRI and conventional angiography [4].

Recently, CTA was significantly improved by increasing scan speed and decreasing section thickness. Ideal image quality depends on two factors; CT angiography technique and data visualization technique [5].

CTA main and great advantage is that it provides minimally invasive dynamic visualization of the whole head and neck vascular circulation. The nearby bones as well as any suspected communication with the intracranial circulation are also easily evaluated [4].

CTA has become the main imaging tool for cervicofacial vascular lesions evaluation (diagnosis), map (guidance) before radiosurgery planning as well as a good follow-up tool for the treated lesions despite of its disadvantage of radiation exposure $[4,5]$.

Vascular lesions management is extremely complex and presence of a MDT is a must for optimal patient outcomes. It includes endovascular procedures and conventional surgery. A combination of embolization and surgical resection has become recently the treatment of choice. The main goal of both is the complete devascularization of the vascular lesion [6].

The most commonly used endovascular procedure is super-selective embolization, a technique in which an embolic agent is delivered via a catheter to obstruct blood flow within a target vessel [6].

Digital subtraction angiography (DSA) is a fluoroscopic technique commonly used in interventional radiology (IR) for accurately delineating blood vessels by removing radiopaque structures like bones [7].

The importance of DSA is to ensure the diagnosis of the vascular lesion in all patients and provide an accurate road map for them; also, treatment can be done in the same sitting $[8,9]$.

Detailed full orientation of the carotid system vascular anatomy is essential for adequate embolization procedure. The external carotid artery (ECA) has multiple branches as the internal maxillary, facial, and superficial temporal arteries are the most important common branches which most of endovascular embolization procedures are done through [8].
As the ECA is embryologically closely linked to the internal carotid artery (ICA), there are few common dangerous anastomotic channels that must be checked during the embolization procedures to avoid possible major complications such as embolic stroke [10].

Embolic agents can be classified according to their chemical ingredients into liquid such as histoacryl, and particulates like polyvinyl alcohol (PVA), as well as coils. Also, they can be classified into temporary and permanent embolic agents according to their duration effect [6].

The aim of this prospective study is to highlight the role of combined CTA and DSA in cervicofacial vascular lesions management.

\section{Methods}

It was a prospective study (from July 2017 to September 2020), conducted on twenty patients referred to the interventional radiology unit who were preliminary diagnosed with cervicofacial vascular lesions with intolerable symptoms such as large cervicofacial swelling with disfigurement, nasal obstruction, and epistaxis (inclusion criteria). Patients with critical medical conditions like heart failure, as well as patients contraindicated for contrast material injection such as those with high renal function tests and those with a given history of severe reaction to previous contrast material injection, were excluded.

The selected patients were evaluated for management by a MDT of an interventional radiologist as well as specialized surgeons whether by endovascular procedures, surgery, or both together.

All patients were subjected to full history taking, clinical examination, and routine laboratory investigations including complete blood picture, coagulation profile, and renal function tests. CTA and DSA were done with subsequent endovascular management of the selected cases to be embolized according to their angiographic data. Anti-coagulant drugs were stopped before any interventions.

Ethical committee approval and detailed written consent from the patients were obtained with explaining risks and benefits.

CTA studies were done using Toshiba Aquilion-CX 64 and 128 slice, including arterial and venous phases. Post-processing reconstruction techniques like threedimensional (3D), multi-planar reformation (MPR), maximum intensity projection (MIP), as well as surface and volume rendering were included. The resulted CTA data were mainly used for confirmation of the diagnosis of the lesion with accurate vascular mapping especially the feeding arteries and if they were unilateral or bilateral as well as draining veins. Another important advantage was to detect any suspected abnormal dangerous 
anastomosis between the internal and external carotid arteries.

Then DSA was done using Philips Allura Xper FD20 machine. DSA is beneficial as it provides more confirmation of the CTA data; also, endovascular embolization could be done at the same sitting.

Based on MDT decision, if the choice was endovascular treatment, subsequent endovascular embolization was done at the angiography suite, under aseptic, nontouch technique. Patients were positioned supine with a headrest, and arms are placed beside the body in extension with support. The given instructions to patients were to stay motionless, especially during image acquisition, and we told them about a potential sensation of warmth within the head with each injection and to avoid swallowing when imaging the neck vasculature, both aimed to reduce motion-related artifacts.

The routine arterial access was the right common femoral artery. A puncture was done under local anesthesia, with/without ultrasound guidance, using standard 18G access needles, and a J-wire (atraumatic curved tip) was used. Then, a 5F arterial sheath is placed in situ with a continuous heparinized saline sheath infusion to prevent peri-sheath clotting.

We started by a cervical arch angiogram, especially if there is suspicion of diseased arch vessel origins, then catheterization of common, internal and external carotid arteries bilaterally using $5 \mathrm{~F}$ vertebral catheter (CORDIS) as a macro-catheter with a hydrophilic 0.035 -in wire such as glidewire (Terumo).

Super-selective catheterization of the small arteries like the internal maxillary artery (according the vascular lesion feeders) was followed, using a $2.7 \mathrm{~F}$ micro-catheter (Progreat $\left.{ }^{\circ}\right)$.

Initial angiograms by macro- and micro-catheters were obtained using anteroposterior, lateral, and $45^{\circ}$ oblique projections to delineate the feeders' pathway as well as to exclude any abnormal ECA-ICA connections.

The used contrast material was OMNIPAQUE ${ }^{\mathrm{TM}} 350$ $\mathrm{mg} \mathrm{I} / \mathrm{ml}$ (Non-ionic contrast material). In CTA, its amount was about $120-150 \mathrm{ml}(1.5 \mathrm{ml} / 1 \mathrm{~kg})$. In DSA alone, it was about $20-30 \mathrm{ml}$ and roughly about $100 \mathrm{ml}$ in case of subsequent embolization. CTA and DSA were done with at least 3-day interval in-between to keep adequate renal functions, which were monitored by renal functioning tests before using the contrast material, with good hydration before and after procedures. We did not face significant contrast material reactions that needed to be controlled.

We used two main different embolic materials, PVA particles as Embosphere $(300-500 \mu \mathrm{m})$ in cases of JNAs and Histoacryl ${ }^{\circ}$ (B. Braun) in cases of AVMs as well as cirsoid aneurysms with concentration of 4:1 or 3:1 (Lipiodol:Histoacryl) according to feeder and draining vein.
Post-embolization angiograms also were obtained to confirm total occlusion of the embolized vascular lesion without any residual active components.

Finally, good hemostasis of the femoral artery puncture site was done using manual compression. Patient neurological examination was a must to ensure a complication-free procedure. Analgesics and antibiotics with good hydration were prescribed to the patients.

\section{Results}

This study was conducted upon 20 patients of different cervicofacial vascular lesions: 16 patients were males $(80 \%)$, and 4 patients were females $(20 \%)$. Seventeen patients were above 40 years (85\%), whereas 3 patients were under 40 years $(15 \%)$. Their ages ranged between 11 and 55 years with a mean age of 26.15 years \pm 12.28 standard deviation (SD).

The most common type we faced was facial AVM which included 10 patients, followed by JNA which included 7 patients, then only 2 patients with cirsoid aneurysms and a single patient with carotid body tumor.

The main complaint was localized swelling in cases of AVMs, cirsoid aneurysms, and carotid body tumor while epistaxis/nasal obstruction in JNAs.

Preoperative embolization was done in 12 patients (60\%) which were all cases of JNAs and large AVMs. Four patients $(20 \%)$ were managed by only embolization as a definitive treatment as they were small AVMs. Four patients only were managed by surgery from the start upon CTA results (two cases of occipital AVMs which are supplied by branches from vertebral artery which was not safe for embolization, one case of post-ligated ECA facial AVM as there were no accessible feeders for embolization, while the last case was carotid body tumor which was not so large and the surgeon was in no need for embolization).

Thirteen cases (65\%) had multiple feeders, while 7 cases (35\%) had a single feeder. Seven cases had feeders from both sides, while 13 cases had a unilateral feeder.

DSA had the same findings to CTA in 15 cases (75\%), while different only in 5 cases $(25 \%)$ as DSA revealed small feeders which were not depicted on CTA.

Regarding the embolic agents, PVA particles were used effectively in 7 patients (44\%) of JNAs and histoacryl in 9 patients (56\%) of AVMs and cirsoid aneurysms (Figs. 1,2 , and 3).

Complete technical success rate was about 94\% (15 case) while partial technical success rate was only $6 \%$ (single case), which was due to a very small accessory feeder that could not be catheterized even with repeated trials (Table 1).

Only 2 cases $(12 \%)$ came back with recurrent lesion after a 3-year follow-up interval which were large $(>7 \mathrm{~cm})$ 


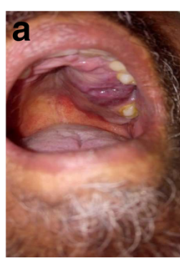

e

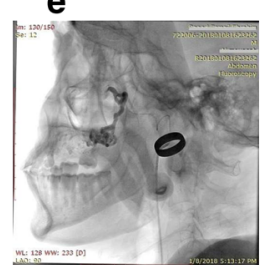

b

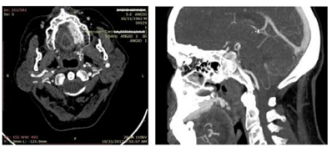

f

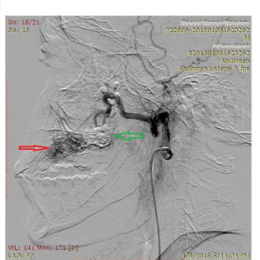

c

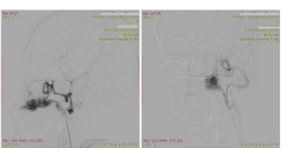

g

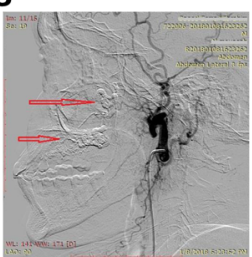

d

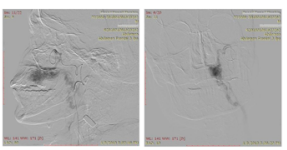

h

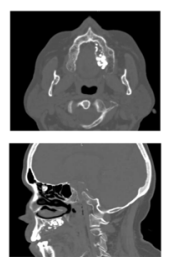

Fig. 1 Male patient presented by a pulsating left-sided upper oral cavity lesion. a A real photo showing bulging bluish lesion in the left side of the oral cavity. $\mathbf{b}$ Axial and sagittal (MIP image) sections of CTA revealing a left-sided buccal AVM. c DSA showing the palatine AVM using the macro-catheter in lateral and AP projections. d DSA showing the palatine AVM using the micro-catheter in lateral and AP projections. e DSA showing the glue material within the AVM which is apparently occluded at post-embolization angiogram super-selectively via the facial artery. $\mathbf{f}$ Another DSA image showed a reisdual active small component (red arrow) nearby the occluded component (green arrow). $\mathbf{g}$ The last postembolization angiogram showing total obliteration of both components of the AVM after superselective catheterization of the feeding branch of the facial artery. $\mathbf{h}$ Non-contrast CT axial and sagittal images showing the retained glue material within the nidus of the AVM after successful embolization

and acquired few collaterals which were managed by reembolization.

\section{Discussion}

Cervicofacial vascular lesions are very challenging to manage and require a MDT. Angiography is the gold standard method of imaging as it offers a detailed assessment of the vascular anatomy, and mostly, treatment can be done at the same sitting. Till now, there is no universally accepted choice of management as these lesions are difficult to treat and have high rates of morbidity and recurrence. Interventional radiology can be used effectively to control them through embolization. Most of these vascular lesions require surgery after embolization as JNAs and large AVMs, yet few lesions are totally cured as in cases of small AVMs [11].

Thanks to the significant rapid change in the practice of interventional radiology, in many cases, less invasive a

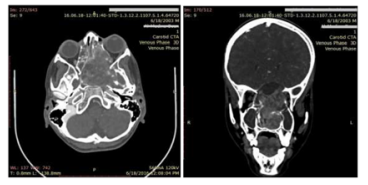

d

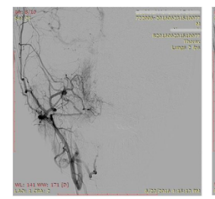

b

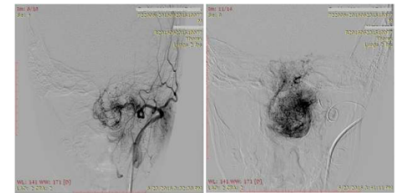

e

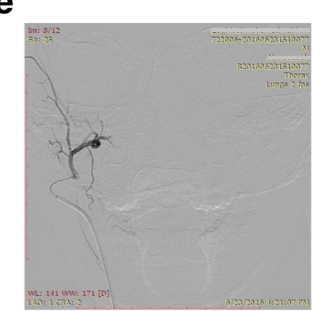

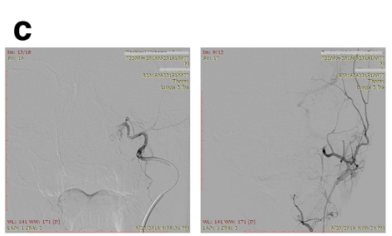

f

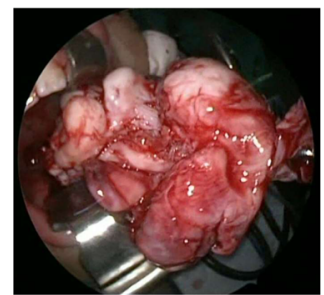

Fig. 2 A 13-year-old male patient presented by epistaxis and nasal obstruction. a Axial and coronal sections of CTA revealing a large hypervascular midline, more at the left side JNA. b DSA showing the aretrial blush of JNA using the macro- and micro-catheter at the left side. $\mathbf{c}$ Postembolization angiogram via PVA particles showing total disappearance of the blush of the JNA through the micro- and macro-catheters after occlusion of the left internal maxillary artery (IMA). d DSA showing the arterial blush of the small right-sided component of the JNA using the macro- and micro-catheter. e Another post-embolization angiogram revealed disappearance of the arterial blush of the small right-sided component of the JNA after occlusion of the right IMA. f Post-embolization endoscopic image showing the excised relatively whitish large JNA which is reflecting adequate devascularization 

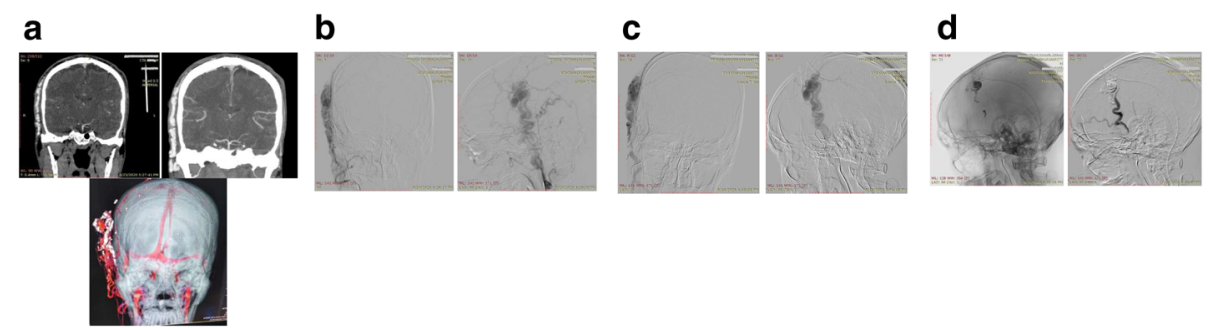

e

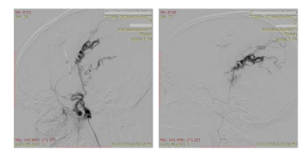

b

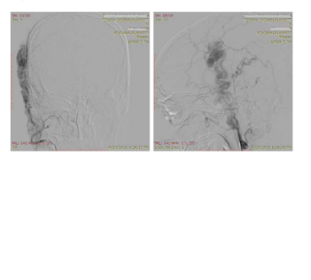

$\mathbf{f}$

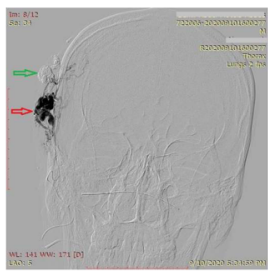

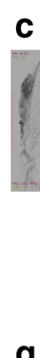

C

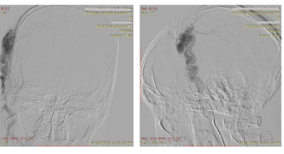

g

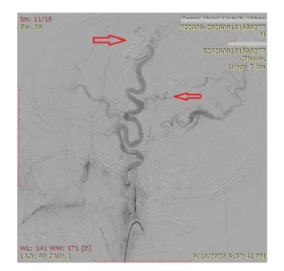

Fig. 3 A 39-year-old male patient presented by a large right frontoparietal cirsoid aneuyrsm. a Coronal sections of CTA demonstrating a large right frontoparietal cirsoid aneuyrsm with MIP and VR images showing the superficial temporal artery as the main feeder. $\mathbf{b}$ DSA showing the cirsoid anueyrsm using the macro-catheter in AP and lateral projections. c DSA showing the cirsoid anueyrsm using the micro-catheter in AP and lateral projections. $\mathbf{d}$ DSA showing glue within the cirsoid anueyrsm which is totally occluded at post-embolization angiogram super-selectively. e Post-embolization angiogram via the macro- and micro-catheters revealed another active small component, which became more evident after occlusion of the original large one. $\mathbf{f}$ Another DSA image showing the residual active small component (red arrow) in the AP projection. Note the superiorly related totally occluded original large one (green arrow). $\mathbf{g}$ Post-embolization angiogram revealed total occlusion of the residual active small component as well as the original large one

techniques such as CTA have replaced DSA as the initial tool in the diagnosis, management planning, and followup of treated patients [12].

Mazora et al. [4] described AVM in two-dimensional (2D) CTA as a brightly enhancing lesion. On 3D images, it appears as a tangle of disorganized vessels rather than the discrete mass appearance of the hemangiomas. Related feeding or draining vessels were abnormally disorganized, prominent, and tortuous. Same findings were described in this study at 2D and 3D images.

The sensitivity of CTA in the diagnosis of vascular disease was $98.4 \%$, specificity was $99.4 \%$, false positive was $1.1 \%$, and false negative was $0.9 \%$. Meifang et al. [13] revealed that CTA examination showed high specificity and sensitivity and low rate of misdiagnosis, with no significant difference with DSA which was observed in most of our cases offering the advantage of non-invasive procedure.

Pedreira et al. [14] revealed no significant difference in recurrence rates in patients receiving immediate (1 day) or delayed (10.6 days) resection after embolization by a 5 -year follow-up interval. In this study, surgical resection was done during the first $72 \mathrm{~h}$ after embolization with a $12.5 \%$ recurrence rate only after a 3-year follow-up interval, as it was the most acceptable time interval for surgeons for a less bloody operation.

Lesion size was a significant predictor for lesion recurrence, with all lesions $>6 \mathrm{~cm}$ in any dimension recurring and none of the lesions $<6 \mathrm{~cm}$ recurring. This is matching with the analysis from Kohout et al. [15] which assumed that smaller lesions resected are most likely to remain in remission while those that are symptomatic and larger are difficult to treat and liable for recurrence. This assumption is nearly matching with these study results as large $(>7 \mathrm{~cm})$ lesions were more liable to recur after embolization in contrast to smaller $(<7 \mathrm{~cm})$ lesions.

With ethanol embolization alone, mostly for cervicofacial AVMs, Do et al. [16] have reported a $68 \%$ success rate (cure and improvement).

In the current study, we did not use the ethanol as an embolic agent so we cannot judge its effectiveness.

Histoacryl (Glue) was the main embolizing agent in this study in cases of AVM including cirsoid aneurysms via trans-arterial approach as onyx was not easily available as well as its cost is high.

Amran et al. [17] demonstrated that the internal maxillary artery (IMA), a branch of the external carotid artery, is the main feeding artery for the JNA.

Routine catheterization of common and external carotid arteries bilaterally was done as $80 \%$ of our cases had bilateral feeders. The commonest feeders were the IMA and ascending pharyngeal artery.

Li et al. [18] retrospectively reviewed 21 patients, 11 of whom received preoperative embolization, and compared them with 10 patients who did not get embolized. There was a significant difference in surgical blood loss and need for blood transfusions, 
Table 1 Distribution of the studied cases according to different parameters $(n=20)$

\begin{tabular}{|c|c|}
\hline Items & No. (\%) \\
\hline \multicolumn{2}{|l|}{ Sex } \\
\hline Male & $16(80 \%)$ \\
\hline Female & $4(20 \%)$ \\
\hline \multicolumn{2}{|l|}{ Age (years) } \\
\hline$\leq 40$ & $17(85 \%)$ \\
\hline $\begin{array}{l}>40 \\
\text { Mean } \pm \text { SD }\end{array}$ & $\begin{array}{l}3(15 \%) \\
26.15 \pm 12.28\end{array}$ \\
\hline \multicolumn{2}{|l|}{ Type } \\
\hline AVM & $10(50 \%)$ \\
\hline JNA & $7(35 \%)$ \\
\hline Cirsoid aneurysm & $2(10 \%)$ \\
\hline Carotid body tumor & $1(5 \%)$ \\
\hline \multicolumn{2}{|l|}{ Management } \\
\hline Preoperative embolization & $12(60 \%)$ \\
\hline Embolization as a final treatment & $4(20 \%)$ \\
\hline Surgery from the start & $4(20 \%)$ \\
\hline \multicolumn{2}{|l|}{ Number of feeders for each lesion } \\
\hline Single & $7(35 \%)$ \\
\hline Multiple & $13(65 \%)$ \\
\hline \multicolumn{2}{|l|}{ Bilaterality of feeding feeders } \\
\hline Bilateral & $7(35 \%)$ \\
\hline Unilateral & $13(65 \%)$ \\
\hline \multicolumn{2}{|l|}{ Identicality of CTA with DSA } \\
\hline Identical & $15(75 \%)$ \\
\hline Not identical & $5(25 \%)$ \\
\hline \multicolumn{2}{|l|}{ Type of the used embolic material } \\
\hline PVA & $9(56.25 \%)$ \\
\hline Histoacryl & $7(43.75 \%)$ \\
\hline \multicolumn{2}{|l|}{ Rate of technical success } \\
\hline Complete success & 15 (93.75\%) \\
\hline Partial success & $1(6.25 \%)$ \\
\hline \multicolumn{2}{|l|}{ Rate of recurrence } \\
\hline Recurrence & $2(12.5 \%)$ \\
\hline No recurrence & $14(87.5 \%)$ \\
\hline
\end{tabular}

favoring the embolization group, and there were no complications from embolization.

Preoperative JNA embolization was very effective in the cases of this study as their surgeons admitted significant decrease in blood loss and operation time as well as amount of packed RBCs needed for transfusion especially in large lesions.

Economopoulos et al. [19] successfully performed preoperative embolization via PVA particles $(150-300 \mu \mathrm{m})$ and gelfoam in 10 of 11 patients with large carotid body tumors, achieving adequate tumor devascularization. Medium-sized PVA particles $(300-500 \mu \mathrm{m})$ was our material of choice in JNA embolization (with/without gelfoam) which achieved good vessel penetration reaching the nidus with subsequent complete occlusion.

Alawneh et al. [20] mentioned the most frequent sites of involvement in scalp AVMs were the frontal, temporal, and parietal regions. The origin of the main feeder is in the subcutaneous tissue of the scalp which originates from the ECA where the superficial temporal artery is most frequently involved one.

At this study, we faced two cases of scalp AVMs with history of trauma (cirsoid aneurysms) which were at the parietal and frontal regions. They were supplied by the superficial temporal artery and effectively embolized by histoacryl followed by resection.

There were few limitations at this study such as the high cost of the used materials in embolization procedures, refusal of few patients to embolization after explaining the possible complications that could happen, and finally the small number of patients diagnosed with these lesions who were seeking for medical advice.

\section{Conclusions}

Combined CTA and DSA is the cornerstone for managing vascular lesions in the cervicofacial region, which necessitates a MDT to decide the most beneficial and least complicated choice for treatment. Endovascular embolization as a preoperative or a terminal procedure is currently more feasible and very effective with minor side effects with more progress in interventional radiology procedures which can adequately solve very challenging cases.

\section{Abbreviations}

CTA: Computed tomographic angiography; MDT: Multidisciplinary team; DSA: Digital subtraction angiography; AVM: Arteriovenous malformation; JNA: Juvenile nasopharyngeal angiofibroma; ECA: External carotid artery

\section{Acknowledgements}

Not applicable

Authors' contributions

HMK: design of the study, data collection, CT image interpretation, statistical analysis, and manuscript writing. MMM: CT image interpretation and manuscript editing. ME: design of the study, CT image interpretation, manuscript editing, sequence alignment. AK: patient referral, manuscript editing, and sequence alignment. SED: design of the study, manuscript editing, and sequence alignment. HMK, MMM, ME, AK, SED: The authors read and approved the final manuscript.

Funding

No sources of funding

Availability of data and materials

The datasets used and/or analyzed during the current study are available from the corresponding author on reasonable request. 


\section{Declarations}

\section{Ethics approval and consent to participate}

This study was approved by the Research Ethics Committee of the Faculty of Medicine at Alexandria University in Egypt on 2019 (reference number is 0201250). All patients included in this study gave written informed consent to participate in this research.

\section{Consent for publication}

All patients included in this research gave written informed consent to publish the data contained within this study.

\section{Competing interests}

The authors declare that they have no competing interests.

\section{Author details}

'Department of Diagnostic and Interventional Radiology, Faculty of Medicine, Port-Said University, Port-Said, Egypt. ${ }^{2}$ Department of Diagnostic and Interventional Radiology, Faculty of Medicine, Alexandria University, Alexandria, Egypt. ${ }^{3}$ Department of Maxillofacial and Vascular Surgery, Faculty of dentistry, Alexandria University, Alexandria, Egypt.

Received: 11 December 2020 Accepted: 18 March 2021

Published online: 30 March 2021

\section{References}

1. Kapadia S, Thakore V, Patel H (2017) Vascular malformations: an update on classification, clinical features, and management principles. Ind J Vasc Endovasc Surg 4(4):152-162. https://doi.org/10.4103/ijves.ijves_57_17

2. Sadick M, Wohlgemuth WA, Huelse R, Lange B, Henzler T, Schoenberg SO, Sadick H (2017) Interdisciplinary management of head and neck vascular anomalies: clinical presentation, diagnostic findings and minimal invasive therapies. Eur J Radiol Open 4:63-68. https://doi.org/1 0.1016/j.ejro.2017.05.001

3. Zhang B, Ma L (2018) Updated classification and therapy of vascular malformations in pediatric patients. Pediatr Invest 2(2):119-123. https://doi. org/10.1002/ped4.12043

4. Mazroa JA, Elrakhawy MM (2012) What can 3D CT angiography add in evaluation of facial vascular lesions? Egypt J Radiol Nucl Med 43(1):67-75. https://doi.org/10.1016/j.j.jnm.2011.12.004

5. Lell MM, Anders K, Uder M, Klotz E, Ditt H, Vega-Higuera F, Boskamp T, Bautz WA, Tomandl BF (2006) New techniques in CT angiography. Radiographics 26(Suppl 1):S45-S62. https://doi.org/10.1148/rg.26si065508

6. Fernández-Alvarez V, Suárez C, de Bree R, Nixon IJ, Mäkitie AA, Rinaldo A, Downer J, Ferlito A (2020) Management of extracranial arteriovenous malformations of the head and neck. Auris Nasus Larynx 47(2):181-190. https://doi.org/10.1016/j.anl.2019.11.008

7. Tateishi H, Kuroki K, Machida H, Iwamoto T, Kariyasu T, Kinoshita Y, Watanabe M, Shiga H, Yuda S, Yokoyama K (2020) Clinical applications of digital angiography with the harmonization function in body interventional radiology. Jpn J Radiol 38(10):922-933. https://doi.org/10.1 007/s11604-020-00990-w

8. Neelakantan S, Samant R, Prasad J, Reddy BN, Reddy P, Das BB et al (2019) Digital subtraction neuroangiography: what a resident should know. J Clin Intervent Radiol ISVIR 03(01):044-052

9. Xun H, Li K, Li X, Liu Y, Du X, Qin Z (2019) Direct percutaneous puncture digital-subtraction-angiography-based classification and treatment selection for soft-tissue arteriovenous malformations of maxillofacial region: a retrospective study. Int J Oral Maxillofac Surg 48(2):181-186. https://doi. org/10.1016/j.jom.2018.07.029

10. Geibprasert S, Pongpech S, Armstrong D, Krings T (2009) Dangerous extracranial-intracranial anastomoses and supply to the cranial nerves: vessels the neurointerventionalist needs to know. AJNR Am J Neuroradiol 30(8):1459-1468. https://doi.org/10.3174/ajnr.A1500

11. McMillan K, Dunphy L, Nishikawa H, Monaghan A (2016) Experiences in managing arteriovenous malformations of the head and neck. Br J Oral Maxillofac Sur 64(1):643-647

12. Wojak JC, Abruzzo TA, Bello JA, Blackham KA, Hirsch JA, Jayaraman MV, Dariushnia SR, Meyers PM, Midia M, Russell EJ, Walker TG, Nikolic B (2015) Quality improvement guidelines for adult diagnostic cervicocerebral angiography: update cooperative study between the Society of
Interventional Radiology (SIR), American Society of Neuroradiology (ASNR), and Society of Neurolnterventional Surgery (SNIS). J Vasc Interv Radiol 26(11):1596-1608. https://doi.org/10.1016/j.jvir.2015.07.002

13. Meifang W, Lianfeng L, Min M, Xiaojie Z, Yani H, (2011) Cerebrovascular disease on brain CTA and DSA comparison, free paper download center 92 11:50:00 28.

14. Pedreira R, Lopez J, Ostrander BT, Pearl M, Puttgen K, Tekes A, Dorafshar AH (2019) An interdisciplinary approach to treatment of adult facial arteriovenous malformations: a review of the literature and a single institution's experience with "late" surgical resection and aesthetic reconstruction. J Craniofac Surg 30(6):1635-1639. https://doi.org/10.1097/ SCS.0000000000005423

15. Kohout MP, Hansen M, Pribaz JJ, Mulliken JB (1998) Arteriovenous malformations of the head and neck: natural history and management. Plast Reconstr Surg 102(3):643-654. https://doi.org/10.1097/00006534-1 99809010-00006

16. Do YS, Yakes WF, Shin SW, Lee BB, Kim DI, Liu WC, Shin BS, Kim DK, Choo SW, Choo IW (2005) Ethanol embolization of arteriovenous malformations: interim results. Radiology 235(2):674-682. https://doi. org/10.1148/radiol.2352040449

17. Amran MY, Bahar A (2019) Case series of pre-operative endovascular embolization of nasopharyngeal angiofibroma using polyvinyl alcohol foam particle: a single centre experience. Open Access Maced J Med Sci 7(15): 2502-2507. https://doi.org/10.3889/oamjms.2019.754

18. Li JR, Qian J, Shan XZ, Wang L (1998) Evaluation of the effectiveness of preoperative embolization in surgery for nasopharyngeal angiofibroma. Eur Arch Otorhinolaryngol 255(8):430-432. https://doi.org/10.1007/s004 050050092

19. Economopoulos KP, Tzani A, Reifsnyder T (2015) Adjunct endovascular interventions in carotid body tumors. J Vasc Surg 61(4):1081-1091.e1082

20. Alawneh K, Abuzayed B, Al Qawasmeh M, Raffee L (2019) Scalp arteriovenous malformation resection with novel technique of endovascular and surgical devascularization. J Craniofac Surg 30(8):2582-2585. https://doi. org/10.1097/SCS.0000000000005670

\section{Publisher's Note}

Springer Nature remains neutral with regard to jurisdictional claims in published maps and institutional affiliations.

\section{Submit your manuscript to a SpringerOpen ${ }^{\circ}$ journal and benefit from:}

- Convenient online submission

- Rigorous peer review

- Open access: articles freely available online

- High visibility within the field

- Retaining the copyright to your article

Submit your next manuscript at $\boldsymbol{\nabla}$ springeropen.com 